\title{
Nanomechanical Infrared Spectroscopy with Vibrating Filters for Pharmaceutical Analysis
}

Kurek, Maksymilian; Carnoy, Matthias; Larsen, Peter Emil; Nielsen, Line Hagner; Hansen, Ole; Rades, Thomas; Schmid, Silvan; Boisen, Anja

Published in:

Angewandte Chemie International Edition

Link to article, DOI:

10.1002/anie.201700052

Publication date:

2017

Document Version

Peer reviewed version

Link back to DTU Orbit

Citation (APA):

Kurek, M., Carnoy, M., Larsen, P. E., Nielsen, L. H., Hansen, O., Rades, T., Schmid, S., \& Boisen, A. (2017). Nanomechanical Infrared Spectroscopy with Vibrating Filters for Pharmaceutical Analysis. Angewandte Chemie International Edition, 56, 3901-3905. https://doi.org/10.1002/anie.201700052

\section{General rights}

Copyright and moral rights for the publications made accessible in the public portal are retained by the authors and/or other copyright owners and it is a condition of accessing publications that users recognise and abide by the legal requirements associated with these rights.

- Users may download and print one copy of any publication from the public portal for the purpose of private study or research.

- You may not further distribute the material or use it for any profit-making activity or commercial gain

- You may freely distribute the URL identifying the publication in the public portal 


\title{
Nanomechanical Infrared Spectroscopy with Vibrating Filters for Pharmaceutical Analysis
}

\author{
Maksymilian Kurek*, Matthias Carnoy, Peter E. Larsen, Line H. Nielsen, Ole Hansen, Thomas Rades, \\ Silvan Schmid and Anja Boisen
}

\begin{abstract}
Standard infrared spectroscopy techniques are welldeveloped and widely used. However, they typically require milligrams of sample and can involve time-consuming sample preparation. A promising alternative is represented by nanomechanical infrared spectroscopy (NAM-IR) based on the photothermal response of a nanomechanical resonator, which enables the chemical analysis of picograms of analyte directly from liquid solution in only a few minutes. Here we present NAM-IR with perforated membranes (filters). The method was tested with the pharmaceutical compound indomethacin by successfully performing a chemical and morphological analysis on roughly $100 \mathrm{pg}$ of sample. With an absolute estimated sensitivity of $109 \pm 15 \mathrm{fg}$, the presented method is suitable for ultrasensitive vibrational spectroscopy.
\end{abstract}

The pharmaceutical industry is in need of simple tools capable of quality control of the drug during the development and production processes. ${ }^{[1]}$ Infrared (IR) spectroscopy, is a widely used drug characterization technique examining the IR light interaction with molecules. The analysis of absorption of radiation associated with the excitation of vibrational modes of molecules provides information about the functional groups of various probed compounds. ${ }^{[2]}$ However, despite constant developments in the field, usually up to few $\mathrm{mg}$ of sample are needed for a single measurement. ${ }^{[3]}$ The analysis of small sample amounts is particularly important in the process of new drug development where sample availability can be strongly limited or in a continuous production line. In addition, for IR analyses, sample pre-concentration and time-consuming preparation, such as freeze drying or $\mathrm{KBr}$ pellet formation, ${ }^{\left[{ }^{4]}\right.}$ are often necessary. In order to reduce the amount of sample material, facilitate its preparation, and improve the flexibility of the IR spectroscopy system, nanomechanical resonators can be employed as photothermal sensors.

Rapid progress in nanofabrication techniques resulted in the emergence of ultrasensitive nanomechanical sensors, commonly consisting of simple vibrating structures such as cantilevers, strings or membranes exhibiting resonance behavior. The principle of operation is based on monitoring of the resonance frequency shift due to various external factors including additional mass, force or temperature change. ${ }^{[5]}$ The high sensitivity of nanomechanical resonators to temperature has already been harnessed to create a group of photothermal spectroscopy devices capable of exceptionally fast chemical analysis of compounds on the femtogram level. ${ }^{[6]}$ However, all previously reported sensors had either single-clamped cantilevers or double-clamped strings as a resonating element. These structures entail a difficult and inefficient coupling of the IR laser beam to the nanometer-wide resonators. Furthermore, commonly used optical motion detection techniques also require precise alignment of the read-out laser spot on the surface of the resonator. ${ }^{[7]}$ Utilizing membranes with a lateral dimension of $1 \times 1$ $\mathrm{mm}$ allows for a simpler alignment of both laser beams. Moreover, membranes give access to a fully integrated magnetic transduction. ${ }^{\text {7a] }}$ This is a significant step towards a real-world application of NAM-IR.

The analyte is directly sampled from liquid solution or dispersion by creating an aerosol, which is streamed through the sensor chip. When the airborne nanoparticles encounter the perforated membrane, functioning as a porous membrane filter, they are collected on its surface by three basic mechanisms assumed to act independently (Figure $1 \mathrm{a}$ and the Supporting Information) ${ }^{\left[{ }^{[8]}\right.}$ [a] M. Kurek, M. Carnoy, Dr. P. E. Larsen, Dr. L. H. Nielsen, Prof. O. Hansen, Prof. A. Boisen

Department of Micro- and Nanotechnology

Technical University of Denmark

Ørsteds Plads, Building 345C, 2800 Kgs. Lyngby (Denmark)

E-mail: makku@nanotech.dtu.dk

[b] Prof. T. Rades

Department of Pharmacy

University of Copenhagen

Universitetsparken 2, 2100 Copenhagen (Denmark)

[c] Prof. S. Schmid

Institute of Sensor and Actuator Systems

TU Wien

Gusshausstrasse 27-29, 1040 Vienna (Austria)

Supporting information for this article is given via a link at the end of the document. 
a)

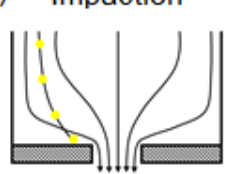

Interception

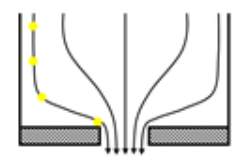

b) Jet nebulizer Vacuum pump

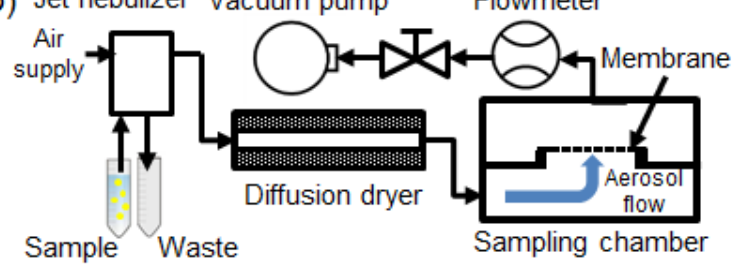

c)
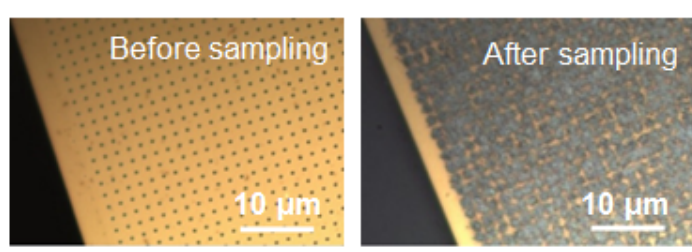

Figure 1. a) Basic sample mechanisms of airborne particles on the porous membrane filter. b) Schematic of the sampling setup. c) Microscopic pictures of silicon rich silicon nitride perforated membrane with $1 \mu \mathrm{m}$ diameter holes distributed in a $1 \mu \mathrm{m}$ grid. Images show the membrane surface before and after sampling of indomethacin.

The absorption spectrum of the collected sample is obtained by illuminating it with monochromatic IR light and simultaneously recording the wavelength specific photothermal detuning of the nanomechanical membrane resonance, as illustrated in Figure 2.

An analytical model of a membrane with a heat source in the center was developed in order to understand the factors contributing to the heat-related resonance frequency detuning of the membrane resonator. For practical reasons, the model is based on a circular instead of a rectangular membrane allowing the derivation of a closed form solution. Furthermore, the perforation was not included in the model. The frequency responsivity, given by the relative resonance frequency change of a circular membrane resonator as a function of absorbed power $P$ in the membrane center, is (see the Supporting Information):

$\frac{\Delta f}{f_{0}} \simeq-\frac{\alpha E}{8 \pi \kappa} \frac{1}{h} \frac{1}{\sigma_{0}}\left(\frac{2-v}{1-v}-0.642\right) P$,

where $\alpha$ is the thermal expansion coefficient, $E$ is the Young's modulus, $K$ is the thermal conductivity, $h$ is the thickness, $\sigma_{0}$ is the tensile stress, and $v$ is the Poisson's ratio of the membrane. As can be seen, the relative frequency shift is proportional to the absorbed power $P$ by the excited sample. Interestingly, the lateral dimensions of the membrane do not affect the sensor
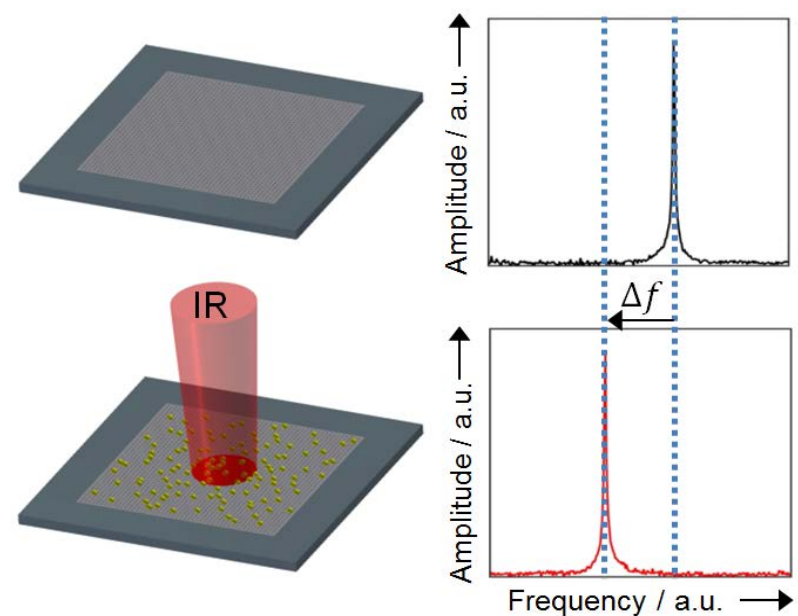

Figure 2. The rectangular membrane vibrates at the resonance frequency defined by its mechanical properties. Due to IR absorption, the vibrational levels of the sample molecules are excited and membrane is subjected to photothermal heating causing the detuning of the resonance frequency.

signal strength. The analytical model was validated with finite element method (FEM). Simulations in COMSOL showed that the difference in the change of the relative frequency for circular and square membrane is less than $1 \%$. The perforation is expected to reduce the tensile stress of a membrane. ${ }^{[9]}$ It was experimentally confirmed that perforated membranes have a higher relative frequency detuning than unperforated membranes of the same dimensions. This can be explained by the decreased thermal conductivity due to the perforation. ${ }^{[10]}$ In our setup, the sampling is done by nebulizing the analyte from a dispersion using a jet nebulizer (Figure $1 \mathrm{~b}$ and the Supporting Information).

Silicon rich silicon nitride $\left(\mathrm{Si}_{x} \mathrm{~N}_{\mathrm{y}}\right)$ rectangular membranes with a thickness of $100 \mathrm{~nm}$ and side length dimension of $1 \mathrm{~mm}$ were fabricated by means of conventional microfabrication techniques. The perforated membranes had circular $2 \mu \mathrm{m}$ in diameter holes organized in $1 \mu \mathrm{m}$ and $2 \mu \mathrm{m}$ grids (see the Supporting Information). Due to the small openings in the membrane, even for moderate flow rates, particles can be accelerated to high velocities of up to $84 \pm 8 \mathrm{~ms}^{-1}$ allowing for operating in the inertial impaction sampling regime. This leads to a significant enhancement of the overall sampling efficiency reaching approximately $59 \pm 21 \%$ for $50 \mathrm{~nm}$ indomethacin particles (see the Supporting Information). This is a great improvement in comparison to similar sampling method used with strings as filter-fibers, with total sampling efficiencies of approximately $10 \%$. ${ }^{[6 b]}$

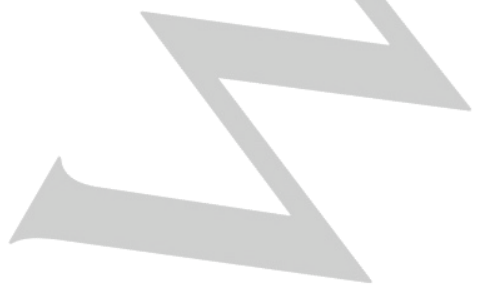




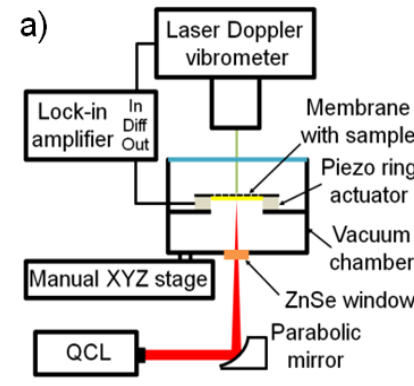

b)

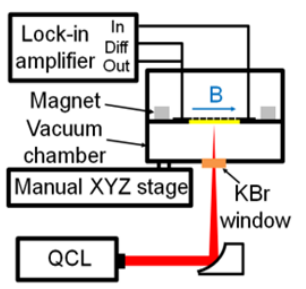

Readout electrode

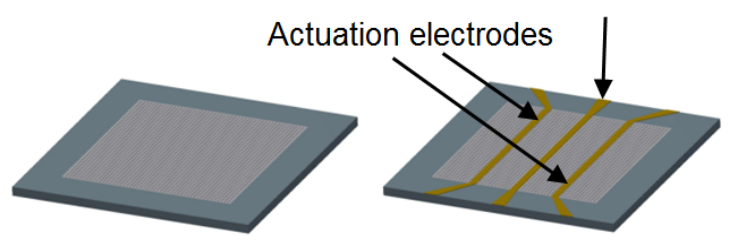

Figure 3. Experimental setup based on a) optical readout and piezo actuation and $b$ ) on magnetic transduction scheme. The IR radiation is emitted in both cases by a QCL.

The measurements were conducted using two separate experimental setups (Figure 3). The main differences between them were the actuation and read-out schemes. The first setup was based on optical detection of the membranes out-of-plane vibration using a laser Doppler vibrometer while the membrane resonator was glued to a piezo ring actuator inside a vacuum chamber. The read-out laser was focused on the top side of the membrane, whereas the IR laser was focused on the back side where the analyte was collected. This approach was already utilized for photothermal IR spectroscopy with nanomechanical string resonators. ${ }^{[6 a, 6 b]}$ However, a laser Doppler vibrometer is an expensive and bulky equipment hindering the application of this technique outside a specialized laboratory. Therefore, a magnetic transduction scheme was applied in which membranes with $10 \mu \mathrm{m}$ wide $\mathrm{Au}$ electrodes were placed between two Halbach arrays of neodymium magnets that intensify the magnetic field over the membrane chip ${ }^{[11]}$ An alternating current was applied to two actuation electrodes for driving the membrane vibration by means of the Lorentz force. The movement of the read-out electrode in the magnetic field induces an electromotive force, which was used to detect the membrane motion. Separation of the actuation and read-out signal paths avoids a complex differential system design for the extraction of the small induced current read-out signal from the strong driving signal (see the Supporting Information). ${ }^{[12]}$

Indomethacin, a commonly used oral nonsteroidal antiinflammatory drug, has been chosen for the proof-of-concept experiments. Indomethacin was dispersed in methanol, nebulized, and sampled on the perforated membrane resonator, as shown in Figure 1c (see also the Supporting Information). Measurements of the fundamental resonance frequency values of the membrane before and after sampling were used to calculate the actual sample mass deposited on the sensor. Assuming a $\mathrm{Si}_{x} \mathrm{~N}_{\mathrm{y}}$ density of $3100 \mathrm{kgm}^{-3},{ }^{[13]}$ it was derived that a total of $124 \pm 9 \mathrm{pg}$ and $118 \pm 11 \mathrm{pg}$ of sample were deposited on the membranes used in the experimental setup with optical and magnetic read-out, respectively. Both samples were then illuminated with IR light from a tunable quantum cascade laser (QCL). The laser duty cycle was set at $0.3 \%$ with pulse duration of $30 \mathrm{~ns}$, repetition rate of $100 \mathrm{kHz}$ and highest power peak of $0.25 \mathrm{~mW}$. The single IR sweep took $100 \mathrm{~s}$ in the wavenumber

a)

b)
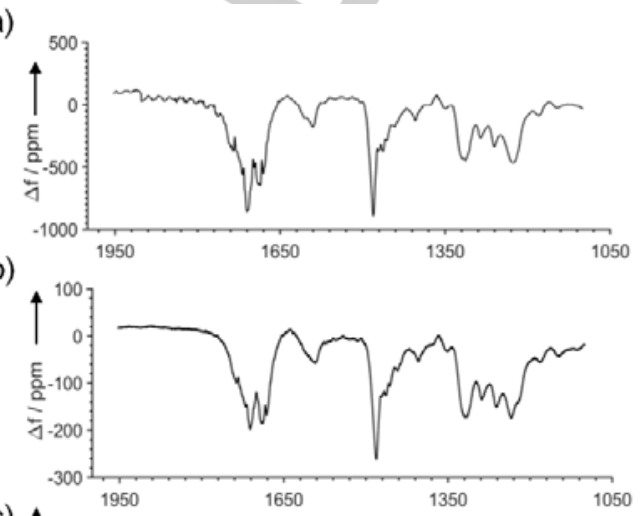

c)

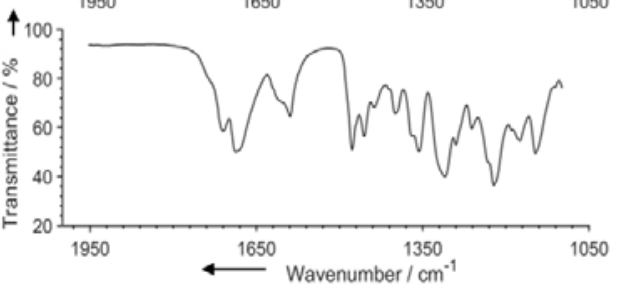

Figure 4. The IR spectra of indomethacin obtained using NAM-IR spectroscopy by a) optical readout and piezo actuation setup, b) magnetic transduction setup. c) Reference FTIR spectra of the analyte.

range from 768 to $1953 \mathrm{~cm}^{-1}$.

Initially, the spectrum of a blank membrane was measured, then the same resonator with indomethacin was analyzed. Subtraction of these two data sets was necessary to remove the background signal from the final indomethacin IR spectrum. The background arose mainly from the high $\mathrm{Si}_{x} \mathrm{~N}_{\mathrm{y}}$ peak at $870 \mathrm{~cm}^{-1}$ and fluctuations caused by the wavenumber dependent power spectrum of the IR laser source (see the Supporting Information).

The recorded spectra of indomethacin using both experimental setups, as well as the reference FTIR spectrum are presented in Figure 4. Both NAM-IR spectra were in good agreement with the FTIR reference. The major peaks measured at 1316, 1481, 1591, 1688 and $1709 \mathrm{~cm}^{-1}$ using the setup with optical read-out and at 1318, 1481, 1594, 1690 and $1712 \mathrm{~cm}^{-1}$ using the setup with magnetic transduction correspond closely to the reference FTIR that showed peaks at 1311, 1478, 1590, 1686 and $1711 \mathrm{~cm}^{-1}{ }^{[14]}$ For instance, the last two peaks located in the ketone bond $\mathrm{C}=\mathrm{O}$ stretching region can be attributed to benzoyl and acid group vibrations. ${ }^{[15]}$ The absolute resonance frequency shift values measured for the last absorption peak were $91 \mathrm{~Hz}$ and $31 \mathrm{~Hz}$ for the two different transduction schemes, which equals to relative frequency shifts of $864 \mathrm{ppm}$ and $197 \mathrm{ppm}$ for optical and magnetic read-out setups, respectively. The lower responsivity to temperature of the sensor operating in the magnetic scheme can be associated with the influence of $\mathrm{Au}$ electrodes. Au has roughly a 100 times larger 
thermal conductivity than $\mathrm{Si}_{x} \mathrm{~N}_{y}$, increasing the heat flow from the membrane to the substrate. However, Au also has a roughly $10 \times$ higher thermal expansion coefficient, which partly counteracts the negative effect of its large thermal conductivity. Assuming a $\mathrm{Si}_{\mathrm{x}} \mathrm{N}_{\mathrm{y}}$ thermal expansion coefficient of $2.3 \cdot 10^{-6} \mathrm{~K}^{-1}$, Young's modulus of $250 \mathrm{GPa}$, thermal conductivity of $2.5 \mathrm{Wm}^{-1} \mathrm{~K}^{-1}$ and Poisson's ratio of $0.23^{[13]}$ it was calculated on the basis of Eq. (1) that the measured frequency shifts were the result of $572 \pm 6 \mathrm{nW}$ and $296 \pm 2 \mathrm{nW}$ of absorbed power in the membranes. For higher duty cycle values of the $\mathrm{QCL}$, melting of the sample was observed, suggesting that the melting point of indomethacin can be reached in our setups. ${ }^{[15]}$

In terms of application of the NAM-IR in pharmaceutica industry, the figure of merit is the smallest amount of sample that can be reliably analyzed. The extracted signal to noise ratio (SNR) at the $1710 \mathrm{~cm}^{-1}$ wavenumber peak was 421 for the optical and 408 for the magnetic setup. In the latter case, the resonance frequency drift caused by Joule heating generated by the electrodes with alternating current was first corrected. The 3sigma sensitivity of the sensor is then given by dividing the total collected sample mass by SNR and multiplying by a factor of 3 , which gives a sensitivity of $\sim 1 \mathrm{pg}$ for both experimental approaches. Considering only the actually probed sample (illuminated by the IR probing light), which constitutes roughly $12 \%$ of the total amount, then as little as $109 \pm 15 \mathrm{fg}$ of sample is sufficient to give a significant signal.

A proper identification of drug crystallinity is crucial as the degree of crystallinity can severely impact the chemical properties and pharmaceutical performance of a compound. ${ }^{[16]}$ Drugs in the amorphous state have a higher aqueous solubility and dissolution rate compared to their crystalline counterparts, ${ }^{[17]}$ and this can result in a higher oral bioavailability of the amorphous drug. The disadvantage of the amorphous form of a drug is that it tends to be less stable, more susceptible to air oxidation and blending effects as well as less reproducible in production in comparison to the crystalline form. Therefore, whilst there is a great interest in using drugs, for instance for oral administration, in their amorphous form, the solid amorphous form of the drug needs to be evaluated during storage, production and dissolution as it is prone to convert to a metastable or stable crystalline form. Characterization of the drug form is usually done by differential scanning calorimetry (DCS), X-ray powder diffraction (XRPD), polarized light microscopy (PLM) or Raman spectroscopy, and these methods can be labor and time intensive. ${ }^{[18]}$ NAM-IR allows for measuring minute amounts of material in powder form or in dispersion in their native state without any sample pretreatment, facilitated by filtration based analyte sampling. Indomethacin in the crystalline and amorphous forms was studied and evident differences in the IR spectra were noticed (Figure 5). The additional peak at wavenumber of $997 \mathrm{~cm}^{-1}$ and peak shift from 1403 to $1413 \mathrm{~cm}^{-1}$ appear for amorphous indomethacin. The membrane with amorphous sample was stored for 4 days at a relative humidity of $48 \%$ and temperature of $22^{\circ} \mathrm{C}$ and new measurement clearly showed that the compound crystallized during the storage period These results were verified by standard FTIR measurements (see the Supporting Information)
In summary, resonating filters were used for photothermal IR spectroscopy. Nebulized particles of the analyte were sampled through impaction on the surface of the filter. The obtained IR spectra match the spectra measured by conventional FTIR spectrophotometry. A new experimental approach based on magnetic actuation and read-out of resonator vibration was introduced and a minimum sample mass required for analysis of $109 \pm 15 \mathrm{fg}$ was achieved. The

a)

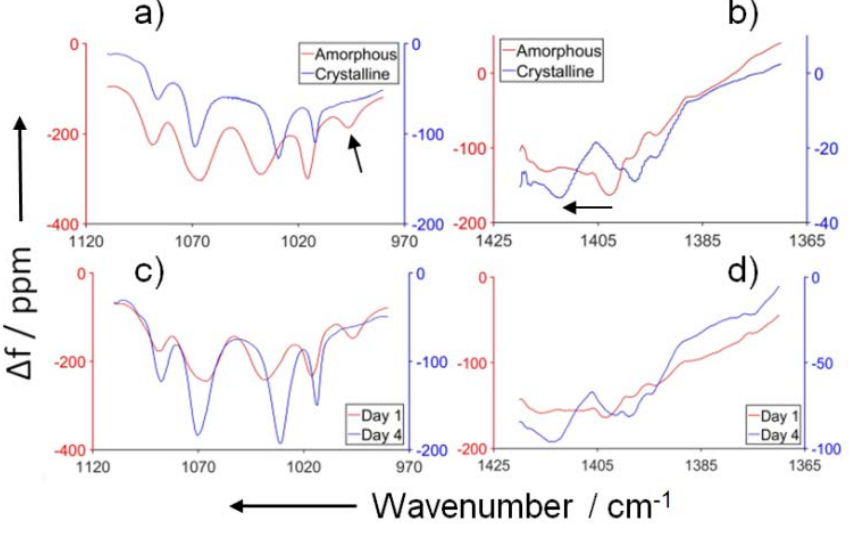

Figure 5. Differences in the IR spectra of amorphous and crystalline indomethacin are observed. The peak at a) $996 \mathrm{~cm}^{-1}$ and b) peak shift from 1403 to $1413 \mathrm{~cm}^{-1}$ appeared for amorphous sample. c) and d) show the effects of crystallization of the amorphous sample.

performance of the magnetic transduction scheme is comparable to the traditionally used laser Doppler vibrometer read-out. NAM-IR simplifies to a great extend the preparation and handling of samples and facilitates on-line and distributed sample collections and measurements in e.g. a drug production line. We believe that such devices have great application perspective in quality and contamination control in pharmaceutical manufacturing.

\section{Acknowledgements}

The authors thank Dr. Korbinian Löbmann at the Department of Pharmacy, University of Copenhagen for helpful comments. The research leading to these results has received funding from the European Research Council under the European Union's Seventh Framework Programme (FP7/2007-2013) / ERC grant agreement $\mathrm{n}^{\circ}$ 320535, the Danish National Research Foundation (DNRF122) and Villum Fonden / grant agreement $\mathrm{n}^{\circ}$ 9301.

Keywords: IR spectroscopy • nanoparticles $\bullet$ nanomechanics $\bullet$ crystallization •

[1] a) D.-K. Bučar, R. W. Lancaster, J. Bernstein, Angew. Chem. Int. Ed. 2015, 54, 6972-6993; b) A. A. Gowen, C. P. O'Donnell, P. J. Cullen, S E. J. Bell, Eur. J. Pharm. Biopharm. 2008, 69, 10-22.

[2] a) P. I. Haris, D. Chapman, Biopolymers 1995, 37, 251-263; b) U. J. Kim, C. A. Furtado, X. Liu, G. Chen, P. C. Eklund, J. Am. Chem. Soc 2005, 127, 15437-15445; c) S. Wartewig, R. H. H. Neubert, Adv. Drug Deliv. Rev 2005, 57, 1144-1170. 
[3] L. H. Nielsen, S. Gordon, J. P. Pajander, J. Østergaard, T. Rades, A. Müllertz, Int. J. Pharm. 2013, 457, 14-24.

[4] M. T. Ansari, S. Karim, N. M. Ranjha, N. H. Shah, S. Muhammad, Arch Pharmacal Res. 2010, 33, 901-910

[5] a) J. Chaste, A. Eichler, J. Moser, G. Ceballos, R. Rurali, A. Bachtold, Nat. Nanotechnol. 2012, 7, 301-304; b) A. K. Naik, M. S. Hanay, W. K. Hiebert, X. L. Feng, M. L. Roukes, Nat. Nanotechnol. 2009, 4, 445-450; c) T. Larsen, S. Schmid, L. Grönberg, A. O. Niskanen, J. Hassel, S Dohn, A. Boisen, Appl. Phys. Lett. 2011, 98, 121901-121903.

[6] a) S. Yamada, S. Schmid, T. Larsen, O. Hansen, A. Boisen, Anal. Chem. 2013, 85, 10531-10535; b) A. J. Andersen, S. Yamada, E. K. Pramodkumar, T. L. Andresen, A. Boisen, S. Schmid, Sens. Actuators B-Chem. 2016, 233, 667-673; c) T. S. Biswas, N. Miriyala, C. Doolin, X Liu, T. Thundat, J. P. Davis, Anal. Chem. 2014, 86, 11368-11372; d) M. F. Khan, S. Kim, D. Lee, S. Schmid, A. Boisen, T. Thundat, Lab Chip. 2014, 14, 1302-1307; e) D. Lee, S. Kim, S. Jeon, T. Thundat, Anal. Chem. 2014, 86, 5077-5082.

[7] a) K. L. Ekinci, Small 2005, 1, 786-797; b) C. Meyer, H. Lorenz, K. Karrai, Appl. Phys. Lett. 2003, 83, 2420-2422; c) E. M. Lawrence, K. E. Speller, D. Yu, Proc. SPIE, 2003, 4980, 51-62.

[8] a) W. C. Hinds in Aerosol Technology, Wiley-Interscience, New York, 1999, pp. 190-205; b) K. R. Spurny, J. P. Lodge, E. R. Frank, D. C Sheesley, Environ. Sci. Technol. 1969, 3, 453-464; c) M. J. Manton Atmos. Environ. 1978, 12, 1669-1675; d) M. J. Manton, Atmos. Environ. 1979, 13, 525-531; e) S. C. Chen, J. Wang, H. Fissan, D. Y. H. Pui, Atmos. Envirom. 2013, 77, 385-393; f) I. Ogura, N. Hashimoto, M Kotake, H. Sakurai, A. Kishimoto, K. Honda, Aerosol Sci. Technol. 2014 48, 758-767; g) I. Ogura, M. Kotake, H. Sakurai, K. Honda, Aerosol Sci. Technol. 2016, 50, 846-856.
[9] M. Pedersen, W. Olthuis, P. Bergeveld, The $8^{\text {th }}$ International Conference on Solid-State Sensors and Actuators 1995, 234-A7, 13-16.

[10] T. Harris, B, Kim, Ch. Reinke, P. Hopkins, T. Olsson, I. El-Kady, E. Shaner, J. Sullivan. IMECE Conference, 2011.

[11] K. Halbach, Nucl. Instrum. Methods 1980, 169, 1-11.

[12] a) X. L. Feng, C. J. White, A. Hajimiri, M. L. Roukes, Nat. Nanotechnol 2008, 3, 342-346; b) K. L. Ekinci, Y. T. Yang, M. H. Huang, M. L. Roukes, Appl. Phys. Lett. 2002, 81, 2253-2255; c) W. J. Venstra, H. J. R. Westra, K. Babaei Gavan, H. S. J. van der Zant, Appl. Phys. Lett 2009, 95, 263103; d) M. Defoort, K. J. Lulla, T. Crozes, O. Maillet, O. Bourgeois, E. Collin, Phys. Rev. Lett. 2014, 113, 136101.

[13] M. T. Alam, M. P. Manoharan, M. A. Haque, C. Muratore, A. Voevodin, J. Micromech. Microeng. 2012, 22, 045001.

[14] a) K. Löbmann, R. Laitinen, H. Grohganz, K. C. Gordon, C. Strachan, T. Rades, Mol. Pharm. 2011, 8, 1919-1928; b) L. S. Taylor, G. Zografi, Pharmaceut. Res. 1997, 14, 1691-1698; c) N. Kaneniwa, M. Otsuka, T. Hayashi, Chem. Pharm. Bull. 1985, 33, 3447-3455.

[15] A. Forster, J. Hempenstall, T. Rades, J. Pharm. Pharmacol. 2001, 53, 303-315.

[16] A. Salari, R. E. Young, Int. J. Pharm. 1998, 163, 157-166.

[17] L. H. Nielsen, S. Gordon, R. Holm, A. Selen, T. Rades, A. Müllertz, Eur. J. Pharm. Biopharm. 2013, 85, 942-951.

[18] a) S. J. Byard, S. L. Jackson, A. Smail, M. Bauer, D. C. Apperley, J. Pharm. Sci. 2005, 6, 1321-1335; b) P. Mura, M. T. Faucci, F. Maestrelli, S. Furlanetto, S. Pinzauti, J. Pharm. Biomed. Anal. 2002, 29, 10151024; c) M. K. Gupta, A. Vanwert, R. I. Bogner, J. Pharm. Sci. 2003, 92, 536-551. 